\title{
Stable and fluctuating temperature effects on the development rate and survival of two malaria vectors, Anopheles arabiensis and Anopheles funestus
}

\author{
Candice L Lyons ${ }^{1,2^{*}}$, Maureen Coetzee ${ }^{2}$ and Steven L Chown ${ }^{3}$
}

\begin{abstract}
Background: Understanding the biology of malaria vector mosquitoes is crucial to understanding many aspects of the disease, including control and future outcomes. The development rates and survival of two Afrotropical malaria vectors, Anopheles arabiensis and Anopheles funestus, are investigated here under conditions of constant and fluctuating temperatures. These data can provide a good starting point for modelling population level consequences of temperature change associated with climate change. For comparative purposes, these data were considered explicitly in the context of those available for the third African malaria vector, Anopheles gambiae.
\end{abstract}

Methods: Twenty five replicates of 20-30 eggs were placed at nine constant and two fluctuating temperatures for development rate experiments and survival estimates. Various developmental parameters were estimated from the data, using standard approaches.

Results: Lower development threshold (LDT) for both species was estimated at $13-14^{\circ} \mathrm{C}$. Anopheles arabiensis developed consistently faster than An. funestus. Optimum temperature $\left(T_{\text {opt }}\right)$ and development rate at this temperature $\left(\mu_{\max }\right)$ differed significantly between species for overall development and larval development. However, $T_{\text {opt }}$ and $\mu_{\max }$ for pupal development did not differ significantly between species. Development rate and survival of An. funestus was negatively influenced by fluctuating temperatures. By contrast, development rate of An. arabiensis at fluctuating temperatures either did not differ from constant temperatures or was significantly faster. Survival of this species declined by c. $10 \%$ at the $15^{\circ} \mathrm{C}$ to $35^{\circ} \mathrm{C}$ fluctuating temperature regime, but was not significantly different between the constant $25^{\circ} \mathrm{C}$ and the fluctuating $20^{\circ} \mathrm{C}$ to $30^{\circ} \mathrm{C}$ treatment. By comparison, previous data for An. gambiae indicated fastest development at a constant temperature of $28^{\circ} \mathrm{C}$ and highest survival at $24^{\circ} \mathrm{C}$.

Conclusions: The three most important African malaria vectors all differ significantly in development rates and survival under different temperature treatments, in keeping with known distribution data, though differences among $\mathrm{M}$ and $\mathrm{S}$ molecular forms of An. gambiae likely complicate the picture. Increasing temperatures associated with climate change favour all three species, but fluctuations in temperatures are detrimental to An. funestus and may also be for An. gambiae. This may have significant implications for disease burden in areas where each species is the main malaria vector.

Keywords: Constant vs. fluctuating temperatures, EIR, LDT, SET, Anopheles, Climate change

\footnotetext{
*Correspondence: candice.lyons@hotmail.com

${ }^{1}$ Centre for Invasion Biology, Department of Botany and Zoology,

Stellenbosch University, Private Bag X1, Matieland 7602, South Africa

${ }^{2}$ Malaria Entomology Research Unit, School of Pathology, Faculty of Health

Sciences, University of the Witwatersrand, Johannesburg, South Africa

Full list of author information is available at the end of the article
} 


\section{Background}

Malaria is Africa's most significant vector-borne disease, accounting for over 200 million clinical cases and well over half a million deaths per year [1]. Although several factors affect malaria prevalence, including the efficacy of control interventions, it depends significantly on the entomological inoculation rate (EIR): the average number of infectious mosquito bites one person receives in a year [2]. The EIR is, in turn, dependent on the human biting rate, which is a product of the number of mosquitoes per human and the number of bites per mosquito. The number of mosquitoes in a population depends on the number of adults entering and leaving the population [3-5], both of which are affected significantly by environmental temperature. Low temperatures tend to limit aquatic stage development and adult activity of some Anopheles species, while extremely high temperatures lead to substantial mortality [6-8]. In the intermediate temperature range, development rate, feeding rate and adult survival increase with temperature, as is true of most ectotherms [9], often leading, in the case of vector-borne disease, to an increase in disease prevalence [3].

Given these relatively straightforward relationships between temperature and significant population parameters $[3,5,10]$, it is perhaps not surprising that forecasts of increasing malaria burden with climate change have been made $[11,12]$. However, such forecasts are controversial for several reasons. First, despite claims that overall the disease burden will increase, several analyses have suggested that in some areas incidence will decrease and in others increase, leading to overall stasis (e.g. [13-15]) or even an overall observed range contraction in regions of stable malaria transmission [16]. When coupled with human intervention, the outcome in many regions should be a decline in disease prevalence. Second, much of the focus has been on changes in mean annual temperature. However, climate change involves more than a change in mean temperatures. Rather, extremes are changing too, with extreme high temperatures being more common than in the past [17]. Moreover, fluctuating temperatures can result in substantially different likelihoods of malaria transmission than constant temperatures $[18,19]$, and the predicted temperature for optimal transmission has also been estimated at lower than previously thought [20]. In consequence, much attention is now being given to developing spatially accurate and biologically more realistic forecasts of changes in malaria prevalence $[4,21,22]$, reflecting a general trend in the field of climate change impact forecasting for vectors and other species [23-25].

Mechanistic models [26,27] provide a useful means to forecast changes in malaria prevalence and can include significant nuances, such as the likely influence of evolutionary change and variation among species, populations and genotypes [26,28]. Nonetheless, they are dependent on the availability of basic physiological data, such as thermal responses, which, though relatively straightforward to collect, are often missing for vectors. Whilst much information is available on temperature effects on major life cycle components of the African vector Anopheles gambiae [7,29-31], much less is known about the thermal biology of the other two major vectors, An. arabiensis and An. funestus [32]. Indeed, one of the most comprehensive recent modeling approaches has highlighted the need for such data for these species [4]. These species are especially important in southeastern Africa, an area for which environmental niche models suggest an increase in disease prevalence with climate change [5,12]. Although recent work has provided comprehensive information on extreme tolerance limits for An. arabiensis and An. funestus [8], the effects of temperature on development and intrinsic survival from egg to adult, have not been as comprehensively investigated (though see $[29,33]$ ). Furthermore, the influence of fluctuations in temperature on development, have not been extensively examined for African malaria vectors, despite the fact that fluctuating temperatures clearly influence other aspects of malaria transmission $[18,19]$, and have long been known to affect anopheline development rate $[34,35]$, as is the case for other insects [36].

This study examined the effects of constant and fluctuating temperatures on the development and survival of the two malaria vectors, An. arabiensis and An. funestus, while also making explicit comparisons with data collected elsewhere for An. gambiae. The results contribute to the information that is required for mechanistic forecasts of likely changes in mosquito population density, and therefore, ultimately, provide experimental data for estimating EIR associated with the change in climate that is taking place across southern Africa, and which is forecast to be substantial in the future [37-40].

\section{Methods}

\section{Colony maintenance and egg collection}

Eggs were collected from two laboratory colonies: the KGB-strain of Anopheles arabiensis originally established from individuals collected in Zimbabwe in 1975; and the FUMOZ-strain of An. funestus originating from individuals collected in Mozambique in 2000 [41]. Although the colonies have shown some laboratory adaptation in thermal responses, these have typically not been pronounced [8].

Colonies are routinely maintained at the insectary temperature of $25^{\circ} \mathrm{C}\left( \pm 2^{\circ} \mathrm{C}\right)$ and relative humidity of $80 \%$ (checked with a Masons thermohygrometer, Brannan, UK), with a 12:12 light/dark cycle and $30 \mathrm{~min}$ 
dusk/dawn simulation. The adults used in these experiments were provided with a $10 \%$ sugar water solution ad libitum and females were provided with a blood meal every alternative day. Anopheles arabiensis usually requires at least two blood meals to produce eggs, while An. funestus requires at least three [42]. Hence, only females that had received at least three blood meals were used for egg collections. Female mosquitoes of each colony were given no longer than half of one dark cycle $(6 \mathrm{~h})$ in which to lay eggs in the provided egg-plates (darkened plastic petri dishes $70 \mathrm{~mm}$ diameter filled with distilled water). This $6 \mathrm{~h}$ period was chosen to allow the chorion of the mosquito eggs to harden before being disturbed (see [42]). Following the $6 \mathrm{~h}$ period, eggs from each species were separated into $200 \mathrm{ml}$ bowls (filled with distilled water) with between 20 to 30 eggs per bowl. Twenty-five bowls were set up per species. These 25 replicates were the basic sample unit used for assessment of development rate at each of several temperatures (i.e. $\mathrm{n}=25$ per temperature): constant temperatures of $15,18,20,22,25,28,30,32$ and $35^{\circ} \mathrm{C}$; and two fluctuating temperature regimes: $15^{\circ} \mathrm{C}$ to $35^{\circ} \mathrm{C}$, and $20^{\circ} \mathrm{C}$ to $30^{\circ} \mathrm{C}$, each with a mean temperature of $25^{\circ} \mathrm{C}$, and the lowest temperature set for the 12 hour scotophase of a 12L:12D cycle. These temperatures were chosen to represent those within which development to adulthood is known to occur in other Anopheles species (e.g. [7,29]). Temperatures were maintained to within $\pm 0.5^{\circ} \mathrm{C}$ through the use of PTC-1 Peltier portable temperature control cabinets (Sable Systems, Las Vegas, Nevada, USA) or through the use of an incubator (SANYO, MIR-154, SANYO Electric Co. Ltd., Osaka, Japan) and were checked using a mercury thermometer. The photoperiod was maintained through non-heating fluorescent tubes connected to a timer. Eggs were maintained under these conditions and larvae reared to eclosion. To prevent eggs from sticking to the sides of replicate bowls, they were washed down using distilled water of the same temperature as each relevant treatment. Larval food comprised a mixture of finely ground dog biscuits and yeast extract. Larvae were fed once or twice daily depending on instar, and adults were killed following eclosion.

\section{Development rate}

All temperature treatments were checked for any developmental change every 8-12 hours depending on stage of development. The positions of replicates were randomized in the incubators. The length of time that $50 \%$ of the population in each replicate took to reach each life stage, and total time to adulthood (again $50 \%$ of the population) was recorded for each of the 25 replicates per temperature treatment and for each species. The $50 \%$ criterion was used because of several substantial outliers, which could not be distinguished as the outcome of delayed egg hatch [43] or experimental artefact, and were therefore given less weight using this procedure. Rate-temperature curves were plotted for each species using $1 /$ mean time $\left(\right.$ days $^{-1}$ ) to larva/pupa/adult emergence per temperature. Using the linear part of the curve for each species (between $15^{\circ} \mathrm{C}$ and $32^{\circ} \mathrm{C}$ for $A n$. arabiensis and between $15^{\circ} \mathrm{C}$ and $30^{\circ} \mathrm{C}$ for An. funestus), ordinary least squares linear regression as implemented in $\mathrm{R}$ (v. 2.15.1) (R Foundation for Statistical Computing, Vienna, Austria) was used to estimate the lower developmental threshold (LDT: -slope/intercept in ${ }^{\circ} \mathrm{C}$ ) and the sum of effective temperatures (SET: 1/slope in degreedays) for each life stage change (i.e. egg, larva, pupa), and for overall development from egg to adult [44-46]. To compare overall development rates between the two fluctuating temperature treatments and their constant mean of $25^{\circ} \mathrm{C}$, an analysis of variance (ANOVA) was used ( $\mathrm{R}$ v. 2.15.1) for each species. Normality and homogeneity of variance were first checked using ShapiroWilk's and Levene's tests, respectively (Additional file 1). In some cases deviations from normality were observed, but generally, few deviations occurred and the model assumptions were met, allowing use of a parametric ANOVA which is reasonably robust and insensitive to deviations from normality, provided designs are balanced [47]. Mean development time in days for each stage and overall across all 11 temperature treatments are shown in Additional file 2. To compare development rates of each stage and for overall development between species, general linear models were implemented in $\mathrm{R}$ (v. 2.15.1) for each stage comparison and overall egg to adult development using temperature and species as categorical predictors in the model and development rates as response variables. Deviations from normality occurred in some instances, but model assumptions were generally met [47,48] (Additional files 3 and 4).

To determine the optimum development temperature $\left(\mathrm{T}_{\mathrm{opt}}\right)$ and the maximum development rate associated with this temperature $\left(\mu_{\max }\right)$ (see [49]), a non-linear curve-fitting approach was adopted using TableCurve 2D (v. 5.01, SYSTAT Software Inc., 2002, San Jose, California, USA) (Additional files 5, 6, 7) (see [49]). $\mathrm{T}_{\text {opt }}$ and $\mu_{\max }$ were determined from the equations for the best fit curve, which differed among stages and between species (Table 1, Additional files 8 and 9). To compare $\mathrm{T}_{\mathrm{opt}}$ and $\mu_{\max }$ of $A n$. arabiensis to that of An. funestus, one replicate for each temperature treatment was selected at random (without replacement) to provide 25 separate curves for overall development rate for each species and for each life stage. The equations used to obtain $\mathrm{T}_{\mathrm{opt}}$ and $\mu_{\max }$ for overall development and development of each stage across all 25 replicates are presented in Additional file 10. Except in a few cases (pupal 
Table 1 Developmental parameters for each life stage and overall, for Anopheles arabiensis and Anopheles funestus

\begin{tabular}{llllll}
\hline Species & Life stage & $\mathbf{T}_{\text {opt }}\left({ }^{\circ} \mathbf{C}\right)$ & $\mu_{\max }\left(\right.$ days $\left.^{-1}\right)$ & LDT $\left({ }^{\circ} \mathbf{C}\right)$ & SET (DD) \\
\hline An. arabiensis & Eggs & 31.1 & 0.7727 & 13.1 & 25.4 \\
\hline & Larvae & 31.1 & 0.208 & 14.3 & 75.8 \\
\hline & Pupae & 28.7 & 1.6109 & 14 & 13.8 \\
\hline An. funestus & Everall & 31.8 & 0.1286 & 13.4 & 137 \\
\hline & Larvae & 31 & 0.5772 & 12.7 & 35.6 \\
\hline & Pupae & 27.3 & 0.9052 & 14.4 & 16.3 \\
\hline & Overall & 31.1 & 0.0813 & 14 & 166.7 \\
\hline
\end{tabular}

Optimum temperature $\left(T_{\mathrm{opt}}\right)$, development rate at the optimum temperature $\left(\mu_{\max }\right)$, lower developmental threshold (LDT) and sum of effective

temperatures (SET in degree-days (DD)) for eggs, larvae, pupae and the overall development of Anopheles arabiensis and Anopheles funestus.

development rates) these equations all had $r^{2}$ values above 0.90 . The same equations for all 25 replicates were chosen to minimize discrepancies when comparing $\mathrm{T}_{\mathrm{opt}}$ and $\mu_{\max }$ between species. $\mathrm{T}_{\mathrm{opt}}$ and $\mu_{\max }$ were then compared, for overall development and for each life stage, between the species using t-tests ( $\mathrm{R}$ v. 2.15.1, R Foundation for Statistical Computing, Vienna, Austria).

\section{Survival}

Although development rate generally increases with increasing temperature up to the optimum [50,51], high development rates are often accompanied by mortality and reduced population output $[7,50,52]$. In consequence, overall survival from egg to adult was recorded as the proportion of eggs that emerged as adults (expressed as a percentage). This \% survival was recorded for all 25 replicates per temperature treatment. To assess differences in survival between the fluctuating temperature treatments and their constant mean $\left(25^{\circ} \mathrm{C}\right)$, a generalized linear model with a binomial distribution of errors and logit link function was used ( $\mathrm{R}$ v. 2.15.1). To illustrate the effect of temperature on survival of each species, mean percentage survival ( \pm standard error) was plotted at each constant temperature and in a comparison between the two fluctuating temperatures and constant mean of $25^{\circ} \mathrm{C}$.

Comparisons between the species examined here and the third major African malaria vector, Anopheles gambiae s.s., were made using data previously gathered for this species [7]. Although this previous work was conducted under different experimental conditions [7], a comparison between development rates and survival of the three species under a range of temperatures is still warranted given that food limitation did not occur and that temperature effects are likely to be the most profound given experimental treatments in both studies.

\section{Results}

\section{Development rate}

Total development rate from egg to adult of $A n$. arabiensis and $A n$. funestus increased between $18^{\circ} \mathrm{C}$ and $32^{\circ} \mathrm{C}$ and between $18^{\circ} \mathrm{C}$ and $30^{\circ} \mathrm{C}$, respectively, in a linear fashion (Figure 1). At $15^{\circ} \mathrm{C}$ and $35^{\circ} \mathrm{C}$, no development from egg to adult occurred in either species (Figure 1). Although, experimentally, no development occurred at $15^{\circ} \mathrm{C}$ and $35^{\circ} \mathrm{C}$, lower developmental thresholds for An. arabiensis and An. funestus were estimated as $\sim 13^{\circ} \mathrm{C}$ and $\sim 14^{\circ} \mathrm{C}$, respectively (Table 1 ). Development rates of each stage, and from egg to adult across all temperatures differed significantly between species, with $A n$. arabiensis showing consistently faster development rates than An. funestus (Table 2). Moreover, the significant temperature"species interaction indicated a steeper slope of the rate-temperature relationship in $A n$. arabiensis (Figure 1) than in An. funestus, reflected in the lower SET value for the former species (Table 1). Species comparisons of $\mu_{\max }$ and $\mathrm{T}_{\text {opt }}$ likewise revealed significantly higher $\mathrm{T}_{\mathrm{opt}}$ and $\mu_{\max }$ for overall development and for larval development in An. arabiensis than in An. funestus (Tables 1, 3), but no significant difference in $\mathrm{T}_{\text {opt }}$ or $\mu_{\max }$ for pupal development, and only significantly different $\mu_{\max }$ for egg development (Table 3). Development rate of $\mathrm{An}$. arabiensis at $25^{\circ} \mathrm{C}$ did not differ significantly from development rate at $15^{\circ} \mathrm{C}$ to $35^{\circ} \mathrm{C}$, although development rate at $20^{\circ} \mathrm{C}$ to $30^{\circ} \mathrm{C}$ was significantly faster than both of these (Figure 2). In contrast, in An. funestus, fluctuating temperatures led to significantly

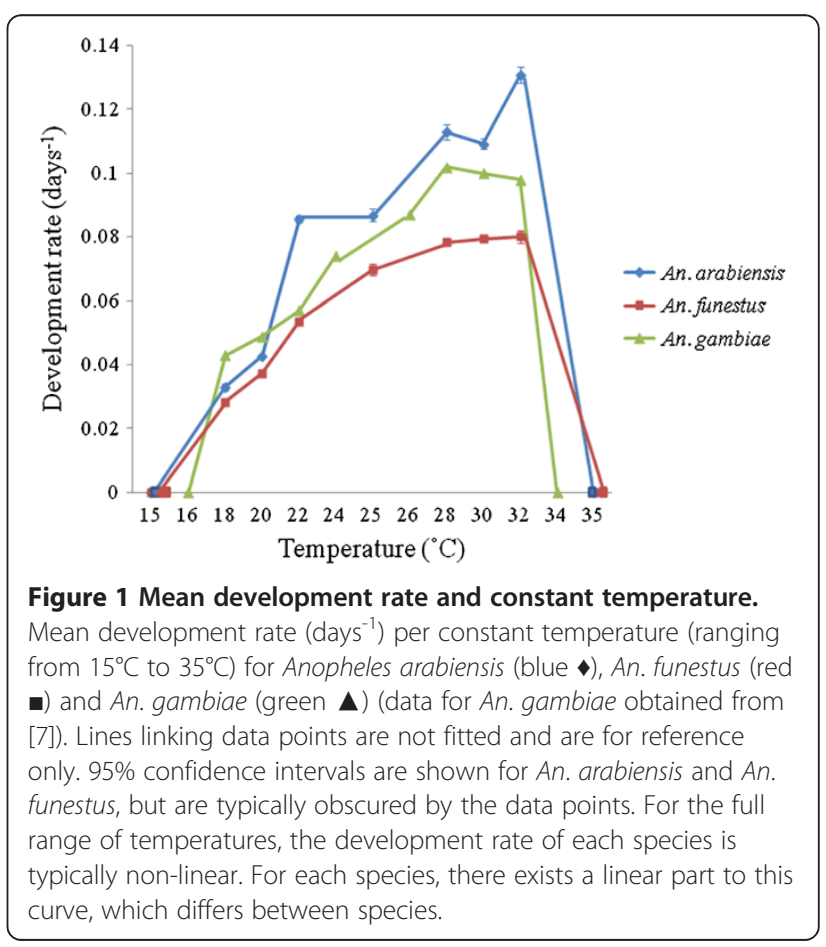


Table 2 Effects of species and temperature on development rates of each life stage and overall development

\begin{tabular}{|c|c|c|c|c|c|}
\hline Stage & Predictor & df & SS & $F$ & P-value \\
\hline Eggs & Temperature & 8 & 2.63 & 80.39 & $<0.0001$ \\
\hline \multirow[t]{2}{*}{$F_{17,432}=184.8 ; P<0.0005$} & Species & 1 & 0.86 & 209.45 & $<0.0001$ \\
\hline & Temperature*Species & 8 & 1.51 & 46.29 & $<0.0001$ \\
\hline Larvae & Temperature & 8 & 0.24 & 213.33 & $<0.0001$ \\
\hline \multirow[t]{2}{*}{$F_{17,432}=460.5 ; P<0.0005$} & Species & 1 & 0.03 & 234.73 & $<0.0001$ \\
\hline & Temperature*Species & 8 & 0.05 & 52.12 & $<0.0001$ \\
\hline Pupae & Temperature & 8 & 8.29 & 8.07 & $<0.0001$ \\
\hline \multirow[t]{2}{*}{$F_{17,432}=20.51 ; P<0.0005$} & Species & 1 & 7.75 & 60.34 & $<0.0001$ \\
\hline & Temperature*Species & 8 & 8.62 & 8.39 & $<0.0001$ \\
\hline Egg to adult & Temperature & 8 & 0.08 & 361.88 & $<0.0001$ \\
\hline \multirow[t]{2}{*}{$F_{17,432}=795.9 ; P<0.0005$} & Species & 1 & 0.02 & 766.33 & $<0.0001$ \\
\hline & Temperature*Species & 8 & 0.02 & 110.25 & $<0.0001$ \\
\hline
\end{tabular}

Results are from general linear models comparing development rates (days ${ }^{-1}$ ) of each stage and from egg to adult, between species, as a function of temperature and species. Model results are shown in the left hand column under each stage comparison.

slower development rates than at $25^{\circ} \mathrm{C}$ (Figure 2). For both species, $\mathrm{T}_{\mathrm{opt}}$ was higher for eggs and larvae than it was for pupae (Table 1).

\section{Survival}

Survival (\%) from egg to adult was highest at $32^{\circ} \mathrm{C}$ for An. arabiensis and at $25^{\circ} \mathrm{C}$ for An. funestus (Figure 3). Complete mortality was found at $15^{\circ} \mathrm{C}$ and $35^{\circ} \mathrm{C}$ for both An. arabiensis and An. funestus (Figure 3). In the case of An. arabiensis, only the $15^{\circ} \mathrm{C}$ to $35^{\circ} \mathrm{C}$ fluctuating temperature led to a significant decline in survival by comparison with the constant $25^{\circ} \mathrm{C}$ conditions (Figure 4), and then only by $c .10 \%$. In contrast, in An. funestus survival was lower in both sets of fluctuating temperature conditions compared with the constant $25^{\circ} \mathrm{C}$, and the reduction in survival was by at least half (Figure 4).

Table 3 Comparing optimum temperatures and development rates at these temperatures, between Anopheles arabiensis and Anopheles funestus

\begin{tabular}{llll}
\hline Life stage & t-value & df & P-value \\
\hline $\mathbf{T}_{\text {opt }}$ & & & \\
\hline Eggs & -0.06 & 48 & 0.9492 \\
\hline Larvae & -2.03 & 48 & 0.0475 \\
\hline Pupae & -1.86 & 48 & 0.0694 \\
\hline Overall & -3.97 & 48 & 0.0002 \\
\hline$\mu_{\text {max }}$ & -16.34 & & \\
\hline Eggs & -18.86 & 48 & $<0.0001$ \\
\hline Larvae & -1.98 & 48 & $<0.0001$ \\
\hline Pupae & -33.71 & 48 & 0.0537 \\
\hline Overall & 48 & $<0.0001$ \\
\hline
\end{tabular}

Results from two-sample t-tests comparing optimum temperature $\left(\mathrm{T}_{\mathrm{opt}}\right)$ and rate of development at the optimum temperature $\left(\mu_{\max }\right)$ of each stage between Anopheles arabiensis and Anopheles funestus.

\section{Discussion}

Of the three major African malaria vector species, $A n$. arabiensis had the fastest overall development rate over a wide range of temperatures. The faster rate by comparison with An. gambiae (illustrated in Figure 1) contrasts with that of at least two previous studies [29,33]. The contrasting outcomes may reflect genotypic differences among the populations used that may have significant effects on a range of traits [53]. Alternatively, the An. gambiae study reared larvae at different densities and under different feeding regimes [7] than the present study which may have influenced the development response of this species to temperature. Nonetheless, both species showed temperature optima for development at c. $32^{\circ} \mathrm{C}$, although the range of temperatures over which development rate is fastest is broader in An. gambiae $\left(28-32^{\circ} \mathrm{C}\right.$, [7]), than it is in $\mathrm{An}$. arabiensis $\left(32^{\circ} \mathrm{C}\right)$. This difference in performance breadth is in keeping with a slightly greater niche width calculated for and generally wider habitat use in An. gambiae than An. arabiensis [53-55], though the significance of the $\mathrm{M}$ and $\mathrm{S}$ molecular forms of An. gambiae [56] in influencing these patterns is not clear. In comparison, An. funestus had a much longer development time than both of these species, with a similar optimum temperature for development, in keeping with its preference for cooler, more permanent and often shaded habitats [53-55].

Temperature also affected survival differently in the three species (see also $[8,30,35,57]$ ). Peak survival was highest at $32^{\circ} \mathrm{C}$ in $A n$. arabiensis, though survival rates were similar between $22^{\circ} \mathrm{C}$ and $32^{\circ} \mathrm{C}$. In An. gambiae survival peaks at $24^{\circ} \mathrm{C}$, and is fairly similar between $22^{\circ} \mathrm{C}$ and $28^{\circ} \mathrm{C}$ [30], dropping rapidly above $30^{\circ} \mathrm{C}$. These differences in survival rate at different temperatures between An. gambiae and An. arabiensis [29] contrast strongly with the situation in An. funestus. A single fairly 


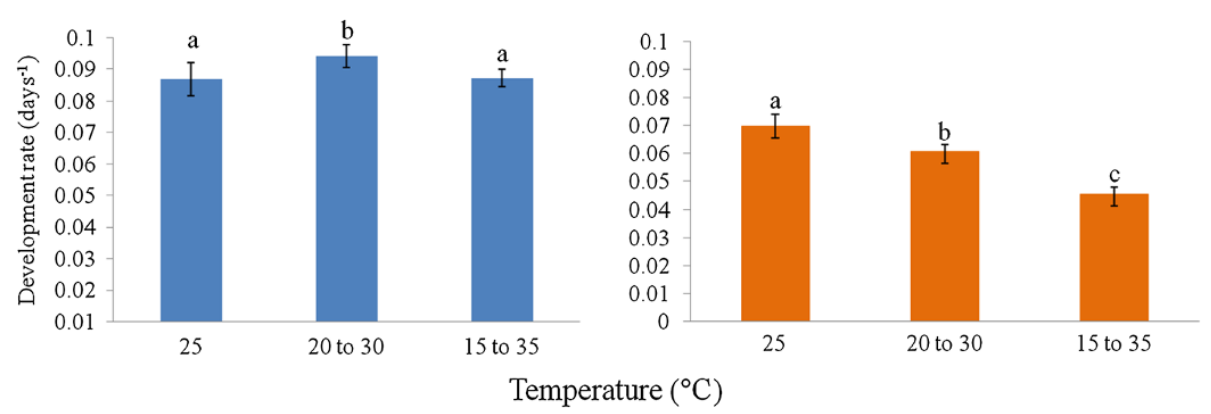

Figure 2 Development rate at constant and fluctuating temperatures. Development rate (days ${ }^{-1}$ ) of Anopheles arabiensis (left) and Anopheles funestus (right) at the two fluctuating temperature regimes and the constant mean of $25^{\circ} \mathrm{C}$. Differences in lower case letters indicate significant differences in development rates (within each species) between the two fluctuating temperature regimes of 20 to $30^{\circ} \mathrm{C}$ and 15 to $35^{\circ} \mathrm{C}$, and their constant mean of $25^{\circ} \mathrm{C}$ (ANOVA: An. arabiensis $\mathrm{df}=2,72, \mathrm{~F}=25.5, \mathrm{P}<0.0001$; An. funestus $\mathrm{df}=2,72, \mathrm{~F}=395.3, \mathrm{P}<0.001$ ). Development at $25^{\circ} \mathrm{C}$ was significantly faster than at fluctuating temperatures for An. funestus but did not differ markedly between treatments for An. arabiensis.

pronounced survival optimum occurred at $25^{\circ} \mathrm{C}$, with substantial declines on either side of this temperature.

The presumably typical exposure of An. arabiensis to fluctuating temperatures, given that it tends to prefer smaller water bodies than does An. funestus $[54,55,58]$ and the greater variability in temperature of smaller ponds $[59,60]$, appears to be reflected in the responses to fluctuating temperatures of development rate and survival in these species. In An. arabiensis, development rate either showed a small, though significant, or no significant response at all to the fluctuating temperatures, and survival declined only marginally (by about $10 \%$ ) at the wider fluctuating temperature $\left(15^{\circ} \mathrm{C}-35^{\circ} \mathrm{C}\right)$, which exposed individuals to temperatures close to their lethal

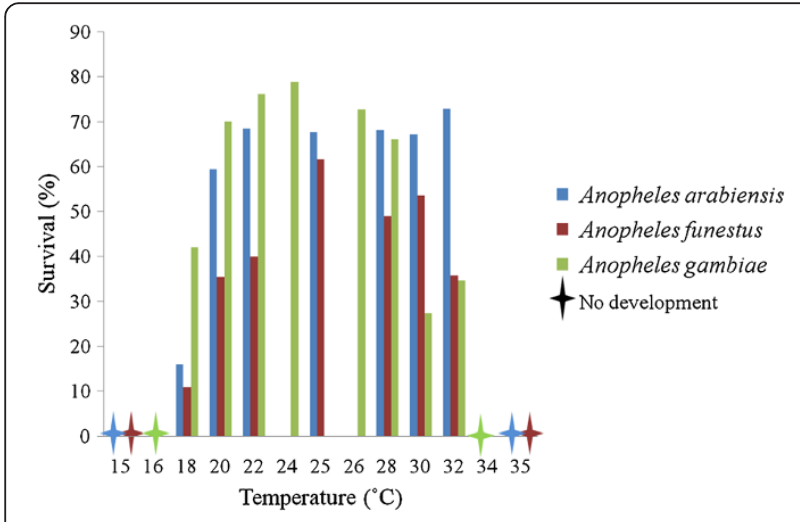

Figure 3 Mean survival at constant temperatures. Mean percentage survival per constant temperature for Anopheles arabiensis (blue), An. funestus (red) and An. gambiae (green) (data for An. gambiae obtained from [7]). Error bars are shown for An. arabiensis and An. funestus. Survival of An. gambiae is highest at the lower end of the temperature range, while survival of An. arabiensis is highest towards the upper end of this temperature scale. An. funestus displays lower survival at all temperatures when compared to the other two vector species. No development and hence, no survival occurred at $15^{\circ} \mathrm{C}$ and $35^{\circ} \mathrm{C}$ for An. funestus and An. arabiensis, while An. gambiae did not develop at $16^{\circ} \mathrm{C}$ and $34^{\circ} \mathrm{C}$. limits [8]. In $A n$. funestus, however, development rate declined significantly with fluctuating temperature (by as much as $30 \%$ at $15^{\circ} \mathrm{C}-35^{\circ} \mathrm{C}$ ), as did survival (from $60 \%$ at $25^{\circ} \mathrm{C}$ to less than half that value at the fluctuating temperatures). The decline in development rate of $A n$. funestus with fluctuating temperatures likely also accounts for the shorter development time recorded here than was found by [35] who estimated development times based on fluctuating field temperatures. What the response is of $A n$. gambiae to fluctuating temperatures is not clear but mesocosm data suggest that fluctuating temperatures are unlikely to have a large effect [33], again acknowledging that differences among the $M$ and $\mathrm{S}$ molecular forms require further exploration.

Overall, the differences found here among the species in their development rate-temperature relationships, optimum temperatures, and responses to fluctuating temperatures, are in keeping with what is known of the regional distributions and more local habitat preferences of the species (e.g. $[53,54,59,61])$. Together they suggest that $A n$. gambiae may be more of a thermal generalist than $A n$. arabiensis, reflected also in the general biology of the species [53,55], and perhaps as a consequence of substantial within-species genetic diversity [56]. Although further studies are required, it also appears the latter species may do best in environments that are too warm for the former. Such differential success under differing environmental conditions is well known in other insects (see [62]). Thus, the explanation for differences in the regional distributions of $A n$. arabiensis and $A n$. gambiae might plausibly be the way local interactions between temperature and water regimes, food availability, duration of breeding site availability, and the significance of what appears to be an asymmetric interaction between the two species [29], scale up to form the regional distribution.

What such an outcome implies is that mechanistic models, of the kind that can take both physiological 


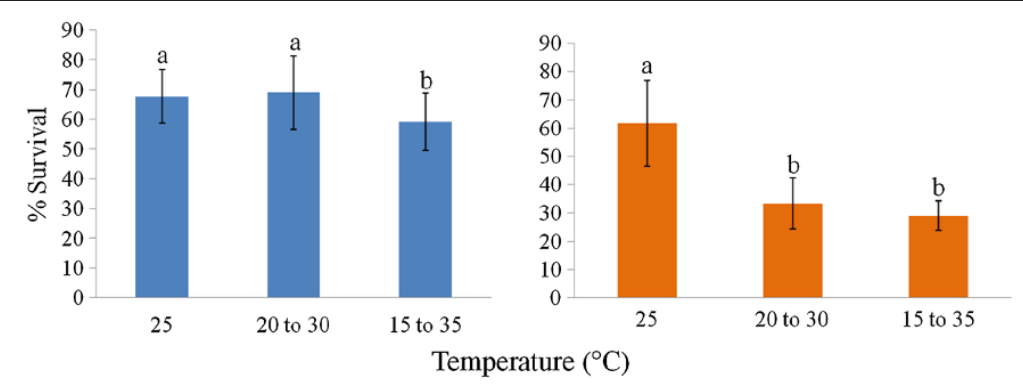

Figure 4 Mean survival at constant and fluctuating temperatures. Mean percentage survival for Anopheles arabiensis (left) and Anopheles funestus (right) between the two fluctuating temperature regimes and constant mean of $25^{\circ} \mathrm{C}$. Differences in lower case letters indicate significant differences in survival between temperature treatments within each species (GLZ with binomial distribution and logit link: An. arabiensis df=2, 72, chi-squared=15.4, $\mathrm{P}<0.001$; An. funestus $\mathrm{df}=2,72$, chi-squared $=164.9, \mathrm{P}<0.0001$ ). Survival of An. arabiensis was only negatively affected at the most variable temperature treatment. Anopheles funestus experienced severely lowered survival at the two fluctuating temperature treatments when compared to the constant $25^{\circ} \mathrm{C}$ treatment.

parameters and the effects of other species into account (e.g. [4]) are likely to perform well for situations where interspecific interactions are dependent on the abiotic environment, a situation likely to be common under natural conditions [62]. In consequence, data such as those provided here would be useful to ensure that further value can be derived from more general models (e.g. [20]). In particular, they would enable substantial differences to be taken into account between species groups, such as the An. gambiae complex and An. funestus, which has slower development rates, shallower ratetemperature relationships, and rather narrow survival limits at $25^{\circ} \mathrm{C}$ in keeping with its preference for more permanent water bodies with emergent vegetation $[54,55]$. Such differential assessments are significant especially because some regions in southern Africa, such as Mozambique, are dominated by An. funestus rather than by members of the An. gambiae complex [63].

Our findings of significant physiological differences among the three major African vectors of $P$. falciparum malaria (see also [8]), also have implications for understanding likely malaria disease burden under changing environments. Most simplistically, it appears that increasing mean temperatures are likely to favour all three species. However, increases in temperature variability and high temperature extremes (as are taking place and are forecast to continue, see $[17,38-40])$ are likely to have more profound impacts on An. funestus and $A n$. gambiae than on An. arabiensis. Indeed, given the apparent negative competitive effects of An. gambiae on $A n$. arabiensis at lower temperatures [29,33], increasing mean temperatures and rising extremes may well further favour the latter. In consequence, simple projections based on environmental niche modelling are unlikely to reflect the vector or disease burden situation into the future because they largely neglect changing species interactions and relative abundances, and the implications thereof given among-species differences in feeding biology (see e.g. [54,63]). Mechanistic models provide a useful way to incorporate such complexity (e.g. [4]), but their outcomes will also have to be informed by the influence of changing local conditions, including habitat change, disease prevention interventions, and social responses to both $[13,55,58,64,65]$, and the effects of fluctuating temperatures on vector competence [19].

\section{Conclusions}

Fluctuating temperatures affect two of Africa's three most prolific malaria vectors differentially, which suggests that the likely impacts of temperature changes associated with climate change will have different impacts on these vector populations. Because of these inherent differences between species, studies should focus on each individual species, so that data used to forecast potential future distributions of malaria vectors in mechanistic models for instance, is as accurate and applicable as possible.

\section{Additional files}

Additional file 1: Results for normality and homogeneity of variance tests from Shapiro-Wilk's and Levene's tests, respectively, for development rate at the constant temperature treatment of $25^{\circ} \mathrm{C}$ and the two fluctuating temperature treatments of $20^{\circ} \mathrm{C}$ to $30^{\circ} \mathrm{C}$ and $15^{\circ} \mathrm{C}$ to $35^{\circ} \mathrm{C}$ for Anopheles arabiensis and Anopheles funestus.

Additional file 2: Average development time (days \pm SD) for $50 \%$ of the population, for each life stage to the next and overall from egg to adult, for each species, Anopheles arabiensis and Anopheles funestus and average \% survival ( \pm S.E.) at each of 11 temperature treatments. No development to the adult stage occurred at $15^{\circ} \mathrm{C}$ or $35^{\circ} \mathrm{C}$ for either species.

Additional file 3: Normal QQ residual plots for comparisons between life stages (eggs, larvae, pupae and total development) of the two species Anopheles arabiensis and Anopheles funestus that meet model assumptions.

Additional file 4: Fitted vs. residual plots of development rates of eggs, larvae, pupae and total development between the two species Anopheles arabiensis and Anopheles funestus. 
Additional file 5: Rate-temperature relationship for overall development from egg to adult of Anopheles arabiensis. The best-fit equation and estimates are shown in the figure title $\left(r^{2}=0.977\right)$.

Additional file 6: Rate-temperature relationship for overall development from egg to adult of Anopheles funestus. The best-fit equation and estimates are shown in the figure title $\left(r^{2}=0.999\right)$.

Additional file 7: Non-linear curve fit for Anopheles gambiae (data from [7]) $\left(r^{2}=0.999\right)$.

Additional file 8: Equations best describing the non-linear relationship between development rate of each stage and overall development from egg to adult, for Anopheles arabiensis and Anopheles funestus (parameter values shown in Additional file 9).

Additional file 9: Parameter estimates for non-linear curve fits for development rate from one stage to the next and from egg to adult (total) for Anopheles arabiensis and Anopheles funestus (equations in Additional file 8).

Additional file 10: Equations used for comparisons between $\mathrm{T}_{\text {op }}$ and $\mu_{\max }$ of Anopheles arabiensis and Anopheles funestus obtained from 25 separate non-linear curves for overall development, and development of each stage.

\section{Competing interests}

The authors declare they have no competing interests.

\section{Authors' contributions}

CLL and SLC conceptualized the experimental design and study. CLL carried out all experiments. CLL, MC and SLC wrote the manuscript. All authors read and approved the final manuscript.

\section{Acknowledgements}

This study was supported by the National Research Foundation through the DST-NRF Centre of Excellence for Invasion Biology, the DST-NRF Research Chair award to MC, and the Stellenbosch University Hope Project. Students and staff of the Vector Control Reference Unit (VCRU) in Johannesburg are thanked for assistance with colony maintenance and establishment. Colony maintenance was undertaken by the Vector Control Reference Unit and all permits for animal maintenance issued to them were valid for these trials (NHLS Animal Ethics Clearance Certificate \#1993047). The authors thank two anonymous reviewers for their comments.

\section{Author details}

${ }^{1}$ Centre for Invasion Biology, Department of Botany and Zoology, Stellenbosch University, Private Bag X1, Matieland 7602, South Africa. ${ }^{2}$ Malaria Entomology Research Unit, School of Pathology, Faculty of Health Sciences, University of the Witwatersrand, Johannesburg, South Africa. ${ }^{3}$ School of Biological Sciences, Monash University, Victoria 3800, Australia.

Received: 22 January 2013 Accepted: 11 April 2013

Published: 16 April 2013

\section{References}

1. World Health Organisation: World Malaria Report. Geneva, Switzerland; 2012.

2. Smith DL, McKenzie FE, Snow RW, Hay SI: Revisiting the basic reproductive number for malaria and its implications for malaria control. PLOS Biol 2007, 5:e42. doi:10.1371/journal.pbio.0050042.

3. Patz JA, Graczyk TK, Geller N, Vittor AY: Effects of environmental temperature on emerging parasitic diseases. Int J Parasitol 2000 30:1395-1405.

4. Parham PE, Pople D, Christiansen-Jucht C, Lindsay S, Hinsley W, Michael E: Modeling the role of environmental variables on the population dynamics of the malaria vector Anopheles gambiae sensu stricto. Malaria J 2012, 11:271

5. Small J, Goetz SJ, Hay SI: Climatic suitability for malaria transmission in Africa, 1911-1995. Proc Natl Acad Sci USA 2003, 100:15341-15345.

6. Love GJ, Whelchel JG: Lethal effects of high temperatures on the immature stages of Anopheles quadrimaculatus. Ecology 1957, 38:570-576.

7. Bayoh MN, Lindsay SW: Effect of temperature on the development of the aquatic stages of Anopheles gambiae sensu stricto (Diptera: Culicidae) Bull Ent Res 2003, 93:375-381.
8. Lyons CL, Coetzee M, Terblanche JS, Chown SL: Thermal limits of wild and laboratory strains of two African malaria vector species, Anopheles arabiensis and Anopheles funestus. Malaria J 2012, 11:226.

9. Hoffmann AA: Physiological climatic limits in Drosophila: patterns and implications. J Exp Biol 2010, 213:870-880.

10. Worner SP: Performance of phenological models under variable temperature regimes: consequences of the Kaufmann or rate summation effect. Environ Entomol 1992, 21:689-699.

11. Tanser FC, Sharp B, le Sueur D: Potential effects of climate change on malaria transmission in Africa. Lancet 2003, 362:1792-1798.

12. Tonnang HEZ, Kangalawe RYM, Yanda PZ: Predicting and mapping malaria under climate change scenarios: the potential redistribution of malaria vectors in Africa. Malaria J 2010, 9:111.

13. Rogers DJ, Randolph SE: The global spread of malaria in a future, warmer world. Science 2000, 289:1763-1766.

14. Thomas C: Malaria: a changed climate in Africa? Nature 2004, 427:690-691.

15. Reiter P, Thomas CJ, Atkinson PM, Hay SI, Randolph SE, Rogers DJ, Shanks GD, Snow RW, Spielman A: Global warming and malaria: a call for accuracy. Lancet Infect Dis 2004, 4:323-324.

16. Thomas CJ, Davies G, Dunn CE: Mixed picture for changes in stable malaria distribution with future climate change in Africa. Trends Parasitol 2004, 20:216-220.

17. Hansen J, Sato M, Ruedy R: Perception of climate change. Proc Natl Acad Sci USA 2012, 109:E2415-E2423.

18. Pascual M, Dobson AP, Bouma MJ: Underestimating malaria risk under variable temperatures. Proc Natl Acad Sci USA 2009, 106:13645-13646.

19. Paaijmans KP, Read AF, Thomas MB: Understanding the link between malaria risk and climate. Proc Natl Acad Sci USA 2009, 106(a):13844-13849.

20. Mordecai EA, Paaijmans KP, Johnson LR, Balzer C, Ben-Horin T, Moor E: MCNally A, Pawar S. Ryan SJ, Smith TC, Lafferty KD: Optimal temperature for malaria transmission is lower than previously predicted. Ecol Lett; 2012. doi:10.1111/ele.12015.

21. Moffett A, Shackelford N, Sarkar S: Malaria in Africa: vector species' niche models and relative risk maps. PLOS ONE 2007, 2:e824. doi:10.1371/journal. pone.0000824.

22. Reid H, Haque U, Clements ACA, Tatem AJ, Vallely A, Masud Ahmed S, Islam A, Haque R: Mapping malaria risk in Bangladesh using Bayesian geostatistical models. Am J Trop Med Hyg 2010, 84:861-867.

23. Martens WJM, Jetten TH, Focks DA: Sensitivity of malaria, schistosomiasis and dengue to global warming. Climatic Change 1997, 35:145-156.

24. Kearney M, Porter WP, Williams C, Ritchie S, Hoffmann AA: Integrating biophysical models and evolutionary theory to predict climatic impacts on species' ranges: the dengue mosquito Aedes aegypti in Australia. Funct Ecol 2009, 23:528-538.

25. Williams CR, Bader CA, Kearney MR, Ritchie SA, Russell RC: The extinction of dengue through natural vulnerability of its vectors. PLoS Neglect Trop D 2010, 4:e922. doi:10.1371/journal.pntd.0000922.

26. Kearney $M$, Porter $W$ : Mechanistic niche modelling: combining physiological and spatial data to predict species' ranges. Ecol Lett 2009, 12:334-350.

27. Buckley LB, Urban MC, Angilletta MJ, Crozier LG, Rissler LJ, Sears MW: Can mechanism inform species' distribution models? Ecol Lett 2010, 13:1041-1054

28. Chown SL, Hoffmann AA, Kristensen TN, Angilletta MJ Jr, Stenseth NC, Pertoldi C: Adapting to climate change: a perspective from evolutionary physiology. Climate Res 2010, 43:3-15.

29. Kirby MJ, Lindsay SW: Effect of temperature and inter-specific competition on the development and survival of Anopheles gambiae sensu stricto and An. arabiensis larvae. Acta Trop 2009, 109:118-123.

30. Bayoh MN, Lindsay SW: Temperature-related duration of aquatic stages of the Afrotropical malaria vector mosquito Anopheles gambiae in the laboratory. Med Vet Entomol 2004, 18:174-179.

31. Rocca KAC, Gray EM, Costantini C, Besansky NJ: 2La chromosomal inversion enhances thermal tolerance of Anopheles gambiae larvae. Malaria J 2009, 8:147.

32. Kirby MJ, Lindsay SW: Responses of adult mosquitoes of two sibling species, Anopheles arabiensis and An. gambiae s.s. (Diptera: Culicidae), to high temperatures. Bull Ent Res 2004, 94:441-448.

33. Paaijmans KP, Huijben S, Githeko AK, Takken W: Competitive interactions between larvae of the malaria mosquitoes Anopheles arabiensis and 
Anopheles gambiae under semi-field conditions in western Kenya. Acta Trop 2009, 109(b):124-130.

34. Huffaker CB: The temperature relations of the immature stages of the malarial mosquito Anopheles quadrimaculatus Say, with a comparison of the developmental power of constant and variable temperatures in insect metabolism. Ann Entomol Soc Am 1944, 37:1-27.

35. Jepson WF, Moutia A, Courtis C: The malaria problem in Mauritius: the bionomics of Mauritian anophelines. Bull Ent Res 1947, 38:177-208.

36. Hagstrum DW, Milliken GA: Modelling differences in insect developmental times between constant and fluctuating temperatures. Ann Entomol Soc Am 1991, 84:369-379.

37. Cox PM, Betts RA, Jones CD, Spall SA, Totterdell IJ: Acceleration of global warming due to carbon-cycle feedbacks in a coupled climate model. Nature 2000, 408:184-187.

38. New M, Hewitson B, Stephenson DB, Tsiga A, Kruger A, Manhique A, Gomez B, Coelho CAS, Masisi DN, Kululanga E, Mbambalala E, Adesina F, Saleh $H_{\text {, }}$ Kanyanga J, Adosi J, Bulane L, Fortunata L, Mdoka ML, Lajoie R: Evidence of trends in daily climate extremes over southern and west Africa. $J$ Geophys Res 2006, 111, D14102. doi:10.1029/2005JD006289.

39. Sanderson MG, Hemming DL, Betts RA: Regional temperature and precipitation changes under high-end $\left(\geq 4^{\circ} \mathrm{C}\right)$ global warming. Phil Trans R Soc A 2011, 369:85-98.

40. Kruger AC, Sekele SS: Trends in extreme temperature indices in South Africa: 1962-2009. Int I Climatol 2012. doi:10.1002/joc.3455.

41. Hunt RH, Brooke BD, Pillay C, Koekemoer LL, Coetzee M: Laboratory selection for and characteristics of pyrethroid resistance in the malaria vector Anopheles funestus. Med Vet Entomol 2005, 19:271-275.

42. Clements AN: The Physiology of Mosquitoes. New York: The MacMillan Company; 1963.

43. Kaiser ML, Koekemoer LL, Coetzee M, Hunt RH, Brooke BD: Staggered larval time-to-hatch and insecticide resistance in the major malaria vector Anopheles gambiae S form. Malaria J 2010, 9:360.

44. Honĕk A, Kocourek F: Temperature and development time in insects: a general relationship between thermal constants. Zool Jahrb Allg Zool 1990, 117:401-439

45. Honĕk A: Geographical variation in thermal requirements for insect development. Eur J Entomol 1996, 93:303-312.

46. Trudgill DL, Honěk A, Li D, van Straalen NM: Thermal time - concepts and utility. Ann Appl Biol 2005, 146:1-4.

47. Quinn GP, Keough MJ: Experimental Design and Data Analysis for Biologists. Cambridge: Cambridge University Press; 2000.

48. Faraway JJ: Linear Models with R. London: Chapman and Hall; 2005.

49. Janion C, Leinaas HP, Terblanche JS, Chown SL: Trait means and reaction norms: the consequences of climate change/invasion interactions at the organism level. Evol Ecol 2010, 24:1365-1380.

50. Clements AN: The Biology of Mosquitoes: Development, Nutrition and Reproduction. Oxfordshire: CABI Publishing; 2000.

51. Chown SL, Nicolson SW: Insect Physiological Ecology: Mechanisms and Patterns. Oxford: Oxford University Press; 2004.

52. Régnière J, Powell J, Bentz B, Nealis V: Effects of temperature on development, survival and reproduction of insects: experimental design, data analysis and modelling. J Insect Physiol 2012, 58:634-647.

53. Sinka ME, Bangs MJ, Manguin S, Coetzee M, Mbogo CM, Hemingway J, Patil AP, Temperley WH, Gething PW, Kabaria CW, Okara RM, Van Boeckel T, Godfray HCJ, Harbach RE, Hay SI: The dominant Anopheles vectors of human malaria in Africa, Europe and the Middle East: occurrence data, distribution maps and bionomic précis. Parasit Vectors 2010, 3:117.

54. Gillies MT, Coetzee M: A supplement to the Anophelinae of Africa south of the Sahara (Afrotropical Region). Johannesburg: Publications of the South African Institute of Medical Research; 1987.

55. Yasuoka J, Levins R: Impact of deforestation and agricultural development on anopheline ecology and malaria epidemiology. Am J Trop Med Hyg 2007, 76:450-460.

56. Lehmann T, Licht M, Elissa N, Maega BTA, Chimumbwa JM, Watsenga FT, Wondji CS, Simard F, Hawley WA: Population structure of Anopheles gambiae in Africa. J Hered 2003, 94:133-147.

57. Lyimo EO, Takken W, Koella JC: Effect of rearing temperature and larval density on larval survival, age at pupation and adult size of Anopheles gambiae. Entomol Exp Appl 1992, 63:265-271.

58. Minakawa N, Munga S, Atieli F, Mushinzimana E, Zhou G, Githeko AK, Yan G: Spatial distribution of anopheline larval habitats in western Kenyan highlands: effects of land cover types and topography. Am J Trop Med Hyg 2005, 73:157-165.

59. Haddow AJ: Measurements of temperature and light in artificial ponds with reference to the larval habitat of Anopheles (Myzomyia) gambiae Giles, and A. (M.) funestus Giles. Bull Ent Res 1943, 34:89-93.

60. Paaijmans KP, Jacobs AFG, Takken W, Heusinkveld BG, Githeko AK, Dicke M, Holtslag AAM: Observations and model estimates of diurnal water temperature dynamics in mosquito breeding sites in western Kenya. Hydrol Process 2008, 22:4789-4801.

61. Lindsay SW, Parson L, Thomas CJ: Mapping the ranges and relative abundance of the two principal African malaria vectors, Anopheles gambiae sensu stricto and An. arabiensis, using climate data. Proc $R$ SOC $B$ 1998, 265:847-854.

62. Chown SL, Terblanche JS: Physiological diversity in insects: ecological and evolutionary contexts. Adv Insect Physiol 2007, 33:50-152

63. Kloke RG, Nhamahanga E, Hunt RH, Coetzee M: Vectorial status and insecticide resistance of Anopheles funestus from a sugar estate in southern Mozambique. Parasit Vectors 2011, 4:16.

64. Omlin FX, Carlson JC, Ogbunugafor CB, Hassanali A: Anopheles gambiae exploits the treehole ecosystem in western Kenya: a new urban malaria risk? Am J Trop Med Hyg 2007, 77:264-269.

65. Mutuku FM, Alaii JA, Bayoh MN, Gimnig JE, Vulule JM, Walker ED, Kabiru E, Hawley WA: Distribution, description, and local knowledge of larval habitats of Anopheles gambiae s.l. in a village in western Kenya. Am J Trop Med Hyg 2006, 74:44-53.

\section{doi:10.1186/1756-3305-6-104}

Cite this article as: Lyons et al: Stable and fluctuating temperature effects on the development rate and survival of two malaria vectors, Anopheles arabiensis and Anopheles funestus. Parasites \& Vectors 2013 6:104.

\section{Submit your next manuscript to BioMed Central and take full advantage of:}

- Convenient online submission

- Thorough peer review

- No space constraints or color figure charges

- Immediate publication on acceptance

- Inclusion in PubMed, CAS, Scopus and Google Scholar

- Research which is freely available for redistribution 